\title{
Effects of Substituting Pawpaw Fruit Puree for Fat on the Sensory Properties of a Plain Shortened Cake
}

\author{
Tiffany D. Wiese and Melani W. Duffrin ${ }^{1}$
}

\begin{abstract}
Additional Index words. Asimina triloba, panel evaluation
\end{abstract}
\begin{abstract}
Summary. The pawpaw (Asimina triloba) is a 3- to 6-inch $(7.6$ to $15.2 \mathrm{~cm}$ ) edible fruit that contains two rows of almond-size seeds surrounded by yellow to orange-colored flesh, with the skin ranging from green to yellow when ripe. The custard-like texture of the pawpaw fruit and its nutrient composition makes it an excellent candidate as a fat-reducing agent in baked goods. Given the properties of the pawpaw fruit, it may prove to be a favorable replacement for fat in various food formulations. The objective of this study was to investigate the sensory properties of plain shortened cake (PSC) using pawpaw fruit puree as a partial replacement for fat in the food formulation. The cakes were prepared by replacing about $25 \%, 50 \%$, and $75 \%$ of the fat with pawpaw fruit puree and were compared to a control using $100 \%$ vegetable shortening. The PSC samples were evaluated using untrained panelists $(n=105)$ with a scorecard using a hedonic scale to measure sensory characteristics. Mean scores suggested that panelists liked all cake samples slightly to extremely. Panelists did not detect differences between the control and $\mathbf{2 5 \%}$ fat replacement sample for all sensory attributes. However, notable preference differences were detected between the control and $25 \%$ samples and the $50 \%$ and $75 \%$ samples for the attributes of color, texture, tenderness, and overall acceptability. Panelists indicated that $25 \%$ fat replacement with pawpaw fruit puree is acceptable in a PSC formula. The notable differences in color, texture, tenderness, and overall acceptability attributes may be overcome with further research and product development. Higher levels of fat replacement may prove to be acceptable in other types of cake formulations and further testing of the various varieties of pawpaw fruit as a fat-replacement in baked goods is warranted.
\end{abstract}

The pawpaw fruit is an oblong fruit ranging from 3 to 6 inches in length and contains one or two rows of almond-size seeds surrounded by a soft, custard-like flesh ranging in color from yellow to orange when ripe. The pawpaw is the largest tree fruit native to the United States and demonstrates potential as a fruit crop with commercial value (Layne, 1996; Peterson, 1991; Pomper et al., 1999). This hardy plant is well adapted to replace old crops that are currently losing value with a new high-value crop. One example of this is that pawpaw orchards could help tobacco (Nicotiana tabacum) farmers to diversify and enhance continued, long-term viability (Layne, 1996). The growing interest in the pawpaw amongst enthusiasts, entrepreneurs, and consumers is raising a demand for more information about uses for the fruit and agricultural production (Cosby, 2001).

School of Human and Consumer Sciences, Ohio University, W345 Grover Center, Athens, Ohio 45701.

We thank Ohio University, Vice President for Research Office and The College of Health and Human Services for the support of this study. Also, Ohio University's 2001 Experimental Foods class assisted with sample preparation, recruitment of panelists, and testing. We would like to thank the course members Andrea Ambrosic, Kelly Dean, Sara Gindlesperger, Stacy Hartman, Lisa Hindenlang, Megan McClincy, Danielle Robertson, Stephanie Sackett, Caitlyn Walker, Brooke Wells, Kim Willard, and Sarah Wilks.

${ }^{1}$ To whom reprint requests should be addressed; e-mail duffrinm@ohio.edu. 
Duffrin etal. (2001) used pawpaw fruit puree as a fat-reducing agent in muffins, compared to muffins made with applesauce and fat. These authors found that muffins made with pawpaw puree $(\approx 91 \%$ fat replacement) were equally acceptable to the other muffins for all characteristics, with the exception of appearance. The study concluded that pawpaw fruit puree had the potential as a carbohydratebased fat reducing agent in muffins and suggested that it had the potential to be used as a fat reducing agent in other types of baked goods. Continued investigation of pawpaw fruit puree as a fat-reducing agent in baked goods develops an area of potential use for this product and provides consumers with another product option that could be used to lower dietary fat intake.

Hydrogenated vegetable oil is used in a plain shortened cake food formulation (Penfield and Campbell, 1990) and contributes to the sensory qualities of flavor, tenderness, and color (Swanson and Munsayac, 1999) in the finished cake product. Although these characteristics are desired in the finished cake product, the trans fatty acid intake associated with the use of hydrogenated vegetable oil is not a desirable component of a heart healthy diet. Trans fatty acids have been found to be a contributor to heart disease by increasing blood cholesterol levels (Jacobs and Murtaugh, 2000; Weisburger, 1997).

Many fruit such as apples (Malus $\times$ sylvestris var. domestica), prunes (Prunus domestica), (Swanson and Munsayac, 1999) and pawpaws (Duffrin et al., 2001) have been used as a fat-reducing agent in baked goods. Using a carbohydrate-based fat-reducing agent in a plain shortened cake would produce a food formulation lower in trans fatty acids, total fat, and calories. The objective of this study was to investigate the effects of substitut- ing varying levels of hydrogenated vegetable oil with pawpaw fruit puree on the sensory properties of a plain shortened cake.

\section{Materials and methods}

Cakes were prepared using a plain shortened cake recipe modified from Penfield and Campbell (1990). The conventional method of mixing was used to prepare the cake batter. The cakes were prepared by replacing about $25 \%, 50 \%$, and $75 \%$ of the fat with pawpaw fruit puree (Integration Acres, Albany, Ohio) and compared to a control using $100 \%$ vegetable shortening. With the exception of the pawpaw, all ingredients were obtained from a local supermarket. The cake formulations are listed in Table 1.

All dry ingredients and eggs were weighed using an electronic scale (Acculab Inc., Newton, Pa.) accurate to $0.1 \mathrm{~g}$. The milk was measured in a $50-\mathrm{mL}$ graduated cylinder and the vanilla was measured in a $10-\mathrm{mL}$ graduated cylinder. The flour, baking powder, and salt were sifted together in a medium-mixing bowl. The vanilla was added to the milk. A handheld electric mixer (model 62520; Hamilton Beach, Picton, Ont., Canada) was used at a speed of 3 for all mixing. The shortening was creamed for $1 \mathrm{~min}$ and the sugar was added and mixed for an additional min. Egg was then added to the creamed mixture and mixed for an additional $2 \mathrm{~min}$. One-third of the flour mixture and one-third of the milk was added and mixed for $45 \mathrm{~s}$, this was repeated twice. The mixing times were kept consistent for each sample preparation. The batter was poured into aluminum anodized round cake pans $[5.1 \mathrm{~cm}$ ( 2 inches) deep and 20.3 $\mathrm{cm}$ (8 inches) diameter (Marpol Inc., Rock Falls, Ill.] that were lightly coated with vegetable oil spray. The samples were baked at $176.7^{\circ} \mathrm{C}\left(350^{\circ} \mathrm{F}\right)$ for
$35 \mathrm{~min}$ and were removed from the pans after cooling for $15 \mathrm{~min}$.

Cake samples $[2.5 \mathrm{~cm}$ ( 1 inch) square] were place on individually coded, square sampling dishes. The four samples were placed on a tray and simultaneously presented to the panelists. Samples were tasted in random order. Participants were provided with tepid (room temperature) water to cleanse the palate between samples. A scorecard with a hedonic scale was used to rate each cake sample for color, flavor, texture, tenderness, aftertaste, and overall acceptability. The scale was composed of eight choices ranging from 1 = like extremely, to $8=$ dislike extremely.

A sample of untrained, volunteer, adult consumer panelists $(\mathrm{n}=105)$ were invited from the university campus to participate in sensory evaluation of the cake samples. Panelists were given information, both verbally and in writing, about the expectations of their participation in the study. After signing a participation consent form, panelists were seated at individual testing stations with standard fluorescent light and given a scorecard with written instructions asking them to rate their cake samples. Descriptive statistics, analysis of variance (ANOVA), and post-hoc analysis (Tukey's honestly significant difference) were completed using the Statistical Package for the Social Sciences (SPSS, Chicago); $P<$ 0.05 was considered significant.

\section{Results and discussion}

Mean scores suggested that panelists liked all cake samples to some degree (slightly to extremely) (Table 2 ). The $25 \%$ sample received more favorable mean ratings in the categories of flavor and texture, although panelists detected no differences between the control and $25 \%$ fat replacement sample for all sensory attributes. ANOVA of

Table 1. Formulations and nutrition analysis of the full-fat plain shortened cake $(\mathbf{1 0 0 \% )}$ and the three variations $(25 \%, 50 \%$, and $75 \%$ ) of fat replacement with pawpaw fruit puree.

\begin{tabular}{|c|c|c|c|c|}
\hline & Control & $25 \%$ & $50 \%$ & $75 \%$ \\
\hline \multicolumn{5}{|l|}{ Ingredients ${ }^{\mathrm{z}}$} \\
\hline Shortening & $120 \mathrm{~g}(1 / 2 \operatorname{cup})$ & $90 \mathrm{~g}(3 / 8 \mathrm{cup})$ & $60 \mathrm{~g}(1 / 4 \mathrm{cup})$ & $30 \mathrm{~g}(1 / 8 \mathrm{cup})$ \\
\hline Pawpaw puree & --- & $32 \mathrm{~g}(1 / 8 \mathrm{cup})$ & $64 \mathrm{~g}(1 / 4$ cup $)$ & $96 \mathrm{~g}(3 / 8 \mathrm{cup})$ \\
\hline \multicolumn{5}{|l|}{ Nutritional analysis ${ }^{y}$} \\
\hline Energy (kcal) & 213 & 186 & 173 & 153 \\
\hline Energy from fat (\%) & 44.4 & 35.1 & 29.2 & 18.6 \\
\hline
\end{tabular}


Table 2. Consumer evaluation of sensory characteristics of plain shortened cakes with $25 \%, 50 \%$, and $75 \%$ of the fat substituted with pawpaw puree and a control cake., ${ }^{z, y}$

\begin{tabular}{|c|c|c|c|c|c|c|}
\hline & Color & Flavor & Texture & Tenderness & Aftertaste & $\begin{array}{c}\text { Overall } \\
\text { acceptability }\end{array}$ \\
\hline Control & $2.5 \mathrm{a}^{\mathrm{x}}$ & $3.2 \mathrm{ab}$ & $3.2 \mathrm{~b}$ & $3.0 \mathrm{~b}$ & $3.2 \mathrm{a}$ & $3.1 \mathrm{~b}$ \\
\hline $25 \%$ pawpaw & $2.6 \mathrm{a}$ & $3.1 \mathrm{~b}$ & $3.0 \mathrm{~b}$ & $3.0 \mathrm{~b}$ & $3.3 \mathrm{ab}$ & $3.1 \mathrm{~b}$ \\
\hline $50 \%$ pawpaw & $3.3 \mathrm{~b}$ & $3.7 \mathrm{a}$ & $4.5 \mathrm{a}$ & $4.4 \mathrm{a}$ & $3.7 \mathrm{ab}$ & $4.0 \mathrm{a}$ \\
\hline $75 \%$ pawpaw & $3.5 \mathrm{~b}$ & $3.4 \mathrm{ab}$ & $4.1 \mathrm{a}$ & $4.0 \mathrm{a}$ & $3.7 \mathrm{~b}$ & $3.7 \mathrm{a}$ \\
\hline
\end{tabular}

data $(P<0.05)$ indicated that there were significant differences amongst samples primarily in the categories of color, texture, tenderness, and overall acceptability. The differences were notable between the control and 25\% samples and the $50 \%$ and $75 \%$ samples. Sensory evaluation scores are summarized in Table 2.

Overall data suggested that a $25 \%$ fat-replacement with pawpaw fruit is acceptable in a plain shortened cake food formulation. The majority of significant differences detected were between the control and $25 \%$ samples and the $50 \%$ and $75 \%$ samples. The increased replacement of fat in the cake samples resulted in a reduced preference for the categories of color, texture, tenderness, and overall acceptability. This is consistent with Swanson and Munsayac's (1999) description of the functionality of fat in baked products.

The nutrient composition and the color of the pawpaw fruit contribute to the color of the final cake product. The results showed that the preference for the color of the cake decreased with the greater addition of the pawpaw fruit. This is consistent with Duffrin et al. (2001) findings in muffins. A difference was detected in the panelists' appearance ratings of the muffins made with pawpaw. Because pawpaws range in color from yellow to orange based on the variety type of the fruit, testing different varieties of pawpaw fruit (Pomper et al., 1999) particularly those lighter in color, as a fat replacement is warranted.

The decreased preference for the texture and tenderness of the samples made with a higher percentage of fat replacement was due to the decrease in the amount of fat in this particular food formulation. Fat is a vital ingredient in baked goods, providing flavor and mouthfeel as well as contributing to appearance, texture, and tenderness of the product (Zoulias et al., 2000). The expectation for this product was a light and fluffy cake, the higher percentages of fat replaced resulted in a reduction of these characteristics. The influence on the color, texture, and tenderness appeared to influence the preference ratings for the category of overall acceptability. Participants preferred the control and $25 \%$ samples in this food formulation.

A high percentage of fat replacement with pawpaw fruit puree in a plain shortened cake recipe did not produce an ideal product. In examining Duffrin et al. (2001) muffin formulation, it appears that some fat is required in a food formulation along with pawpaw fruit puree for a desirable product. This point warrants further investigation in determining appropriate proportions of fat substitution using pawpaw fruit puree in a variety of baked good food formulations.

In conclusion, the results obtained from this study are useful for informing consumers about the potential uses of pawpaw fruit as a carbohydrate-based fat-reducing agent in baked products. Food and nutrition professionals can educate their clients about the added benefits of substituting some of the hydrogenated vegetable oil in recipes with pawpaw fruit puree. The benefits of using pawpaw as fat-reducing agent include: less trans fatty acids and total fat in the baked good, less calories, and added nutritional benefits.

\section{Literature Cited}

Cosby, J.F. 2001. Growers, biologists search for new pawpaw markets. Farm World (Oct.) 17:7 .

Duffrin, M.W., D.H. Holben, and M.J. Bremner. 2001. Consumer acceptance of pawpaw (Asimina triloba) fruit puree as a fat-reducing agent in muffins, compared to muffins made with applesauce and fat. Family Consumer Sci. Res. J. 29:281-287.

Jacobs, D.R. and M.A. Murtaugh, 2000. It's more than an apple a day: An appropriately processed plant-centered dietary pattern may be good for your health. Amer. J. Clinical Nutr. 72:899-900.

Layne, D.R. 1996. The pawpaw [Asimina triloba (L.) Dunal.]: A new fruit crop for Kentucky and the United States. HortScience 31:777-784.

Penfield, M.P. and A.M. Campbell. 1990. Experimental food science. $3^{\text {rd }}$ ed. Academic Press, San Diego, Calif.

Peterson, R.N. 1991. Pawpaw (Asimina). Acta Hort. 290:567-600.

Pomper, K.W., D.R. Layne, and R.N. Peterson. 1999. The pawpaw regional variety trial, p. 353-357. In J. Janick (ed.). Perspectives on new crops and new uses. ASHS Press, Alex., Va.

Swanson, R.B. and L.J. Munsayac. 1999. Acceptability of fruit purees in peanut butter, oatmeal, and chocolate chip reduced-fat cookies. J. Amer. Dietetic Assn. 99:343-345.

Weisburger, J.H. 1997. Dietary fat and risk of chronic disease: Mechanistic insights from experimental studies. J. Amer. Dietetic Assn. 97:S16-S23.

Zoulias, E.I., V. Oreopoulou, and C. Tzia. 2000. Effect of fat mimetics on physical, textural and sensory properties of cookies. Intl. J. Food Properties 3:385-397. 